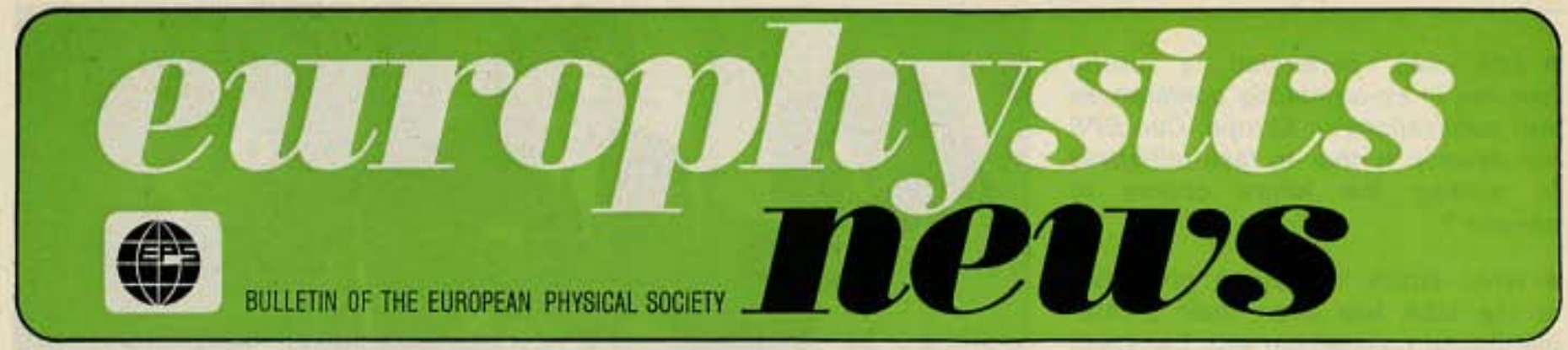

\section{Viewpoint}

\section{6,500}

believe it or not, is the number of copies of this issue of Europhysics News which have been sent to individual physicists. By an exceptional effort of inter-society cooperation, Europhysics News has reached a unique position of real potential as a sounding board for the European physics community. One recent example has been the response to the paper by K. Ganzhorn earlier this year. You are invited to put forward your ideas for European physics in a Letter to the Editor' - if you have any ideas on the subject !

\section{6,500}

but are we satisfied? Well no, because the number could be greater. For example, does your librarian know that Europhysics News is available at only Sw. Fr. 15 for the ten green issues and $\mathrm{Sw}$. Fr. 10 for the two yellow Meetings Issues?.

\section{6,500}

but are you satisfied? If you are, then perhaps you could recommend Europhysics News and EPS membership to your colleagues. (By the way, if you receive Europhysics News and are not already an Individual Ordinary Member of EPS, it is only Sw. Fr. 18 per year.) On the other hand, if you are not satisfied, then we would like to hear how Europhysics News can do better for you and for the European physics community.

\section{Contents}

Viewpoint

Interview with H.B.G. Casimir, President of EPS .

Highlights of Oslo Council Meeting

Physics policy discussion

Nobel Lecture

Astronomy and Astrophysics

Society News

Meetings
1

3

6

8

10

11

12

\title{
H.B.G. Casimir President of EPS
}

\section{An interview with the Editor, Alex Crawford}

- Professor Casimir, you have been closely associated with EPS since its formation in 1968. What view do you have of its development so far ?

- Although I was associated with the formation of EPS, and attended the Foundation in Geneva in September 1968 , I have not found time owing to the pressure of my work, to follow subsequent developments closely. However, I have been impressed with the achievements of EPS in the field of publications and conferences. Another important aspect of the EPS activities has been their contribution to understanding between Eastern and Western European countries. Those are the two major fruits of EPS development so far.

- Both of your predecessors as President have been academic physicists. Do you envisage that your background in industrial development will lead to a reorientation of EPS during your Presidency?

- Well, my first reaction to this question must be to answer 'No' - for several reasons. Throughout the 30 years of my work in industrial research, I have always been in touch with academic science, and I maintained a strong attachment to theoretical physics during this time. After all, I do not believe that the difference between industrial research and academic science is so real as might appear, especially in fields like solid state physics. The motivation might be different, but the way of handling problems is the same.

On the other hand, I would hope to be able to contribute to the understanding between industrial research workers and academics. I believe that this would be a worthwhile activity for me as President of EPS.
- At present, virtually all science policy in Europe is determined at national level. Can EPS have an effective influence on science policy makers? Is there not a need for a group within EPS to concentrate on strategy and longer term planning?

- One must, of course, be aware of the limitations in this field. Even if there are meetings to discuss science policy at an international level, these are generally handled by government officials and not by scientists. I should think that CERN is about the only case in which scientists have been allowed a relatively free hand. However, EPS could ensure that it would be prepared to advise such international meetings on science policy by providing spokesmen.

In the case of the science policy makers at a national level, some of these might be physicists and so EPS could make its views known in this way.

Perhaps I should comment here that I have had four years as the President of EIRMA (European Industrial Research Management Association) which has over 100 member firms. My experience has shown the undoubted value of the EIRMA contacts in supporting the arguments of industrial research managers within their own companies. If the industrial managers refer to the consensus reached at EIRMA meetings, then their views have outside support, appear more objective and are less easy to set aside. Perhaps EPS might provide a forum in a similar fashion. However, I would say that the emphasis should be on agreeing 'rules of the game' for formulating science policy, and not interference in detail in the policies of different countries. 
- EPS has performed a useful function in co-ordinating conferences and publications in Europe. Can EPS not develop further to take initiatives in guiding the future course of physics?

- What struck me about physicists in the USA has been their greater mobility in comparison with European physicists - both in terms of moving from place to place and from industry to industry. I believe that such mobility is healthy and should be encouraged. Of course, there are those who have said to me that 'A rolling stone gathers no moss'. But then, have never thought that mossgathering was an activity for physicists !

In Europe, however, the mobility of physicists has been impaired for three major reasons. First, there is the suspicion of employers, and not only industrial employers ; even universities may be reluctant to engage people from other countries. Then there are the formal difficulties of moving from one country to another: degrees might not be recognized and a certain career structure may be insisted upon. Finally, there is the sociological aspect. It is my personal opinion that the employers' suspicions are largely unjustified and I believe that they suffer for them. Whilst the problems of the adaptation of individuals and their families might often prove insurmountable, I would hope that, through EPS, I might contribute usefully to overcoming the formal difficulties that physicists ex-

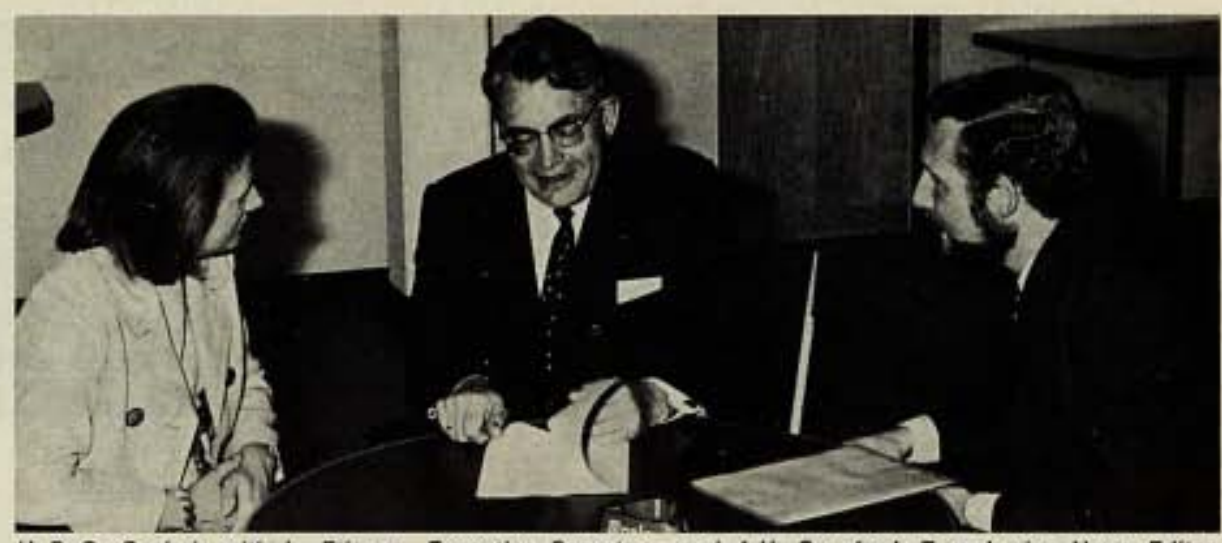

H. B. G. Casimir with L. Etionne, Executivo Secretary, and A.H. Crawford, Europhysics News Editor. at the conference on The Impact of Computers on Physics at CERN.

perience in obtaining positions outside their home countries.

- Physicists in basic research in developed countries are finding it more difficult to obtain funds for their activities. Is it possible to justify their claims on the basis that their results are the data banks for future industrial applications?

- This question is very important, but it is one that is difficult to answer in a few sentences. That 'science for its own sake' leads to results and capabilities which would not otherwise appear - that is irrefutable. A society shows that it has raised itself above the subsistence level when it can set aside some time for scientists to investigate non-utilitarian problems. I would say that there is also the need for good applied research, and the decision on where the equilibrium lies is extremely difficult. However, I think that we should not try to base the provision for basic research exclusively on utilitarian grounds.

\section{H.B.G. CASIMIR}

Hendrik Brugt Gerhard Casimir was born on 15 July 1909 in The Hague. His publications have included many $\mathrm{He}$ studied theoretical physics at papers on theoretical physics, applied Leyden with Ehrenfest, at Copenhagen mathematics and low temperature with Niels Bohr and at Zurich with physics.

Pauli, and obtained his Ph.D. at Leyden in 1931. Before joining the Research Laboratories of Philips at Eindhoven in 1942, he had held research positions at Leyden. In 1946 , Casimir became a Director of the Research Laboratories and a member of the Board of Management of the Philips Company in 1957. In this capacity, he supervises the research activities of all Philips laboratories in a number of countries.

Apart from his membership of the Royal Netherlands Academy of Sciences and Letters, Casimir is a member of the eight Academies and holds six honorary degrees in other coun- tries. He is a Knight in the Order of the Netherlands Lion, and is on the Board of Trustees of the Rockefeller

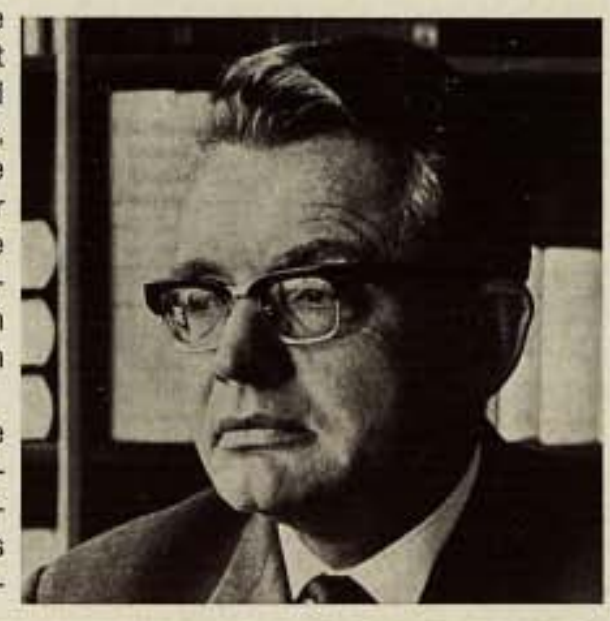

- Within EPS, there has been much debate about centralization versus decentralization. Is it not the case that a society can only be effective if it maintains a strong co-ordinating executive to work towards the goals set by the policy makers?

- In all industrial research establishments, I have noticed that there have been the 'centralizers' who wanted to gather everyone together in big laboratories, and the 'decentralizers' who were all for forming small research groups. I believe there is a universal tendency for there to be such arguments. My position has never been wholly in one direction or in the other. I would advocate adopting the approach which works best for handling the tasks that have to be performed, although I might lean a little towards decentralization.

- So far, EPS has played its part only on the European stage. Are the roles which EPS could sensibly perform on the world scale?

- EPS must not have grandiose notions, but much can be achieved by sending information to national societies outside Europe and by inviting international speakers to Europhysics conferences. In this way. EPS can play a part in developing friendly contacts between physicists throughout the world.

- Finally, Professor Casimir, what do you see as the most urgent tasks and essential objectives of EPS during your Presidency?

- At this stage, I would like to spend some time finding out more about the previous work of EPS, and then I would be willing to formulate a programme for EPS. However, one area to which some attention could be given is the teaching of physics. Also I would return to my former point about the worthwhile nature of breaking down the impediments to the mobility of physicists. 